\title{
Prevalence and antimicrobial susceptibility of Escherichia coli 0157 in beef at butcher shops and restaurants in central Ethiopia
}

\author{
Ashenafi Feyisa Beyi ${ }^{1,2^{*}}$, Akafete Teklu Fite ${ }^{1}$, Ephrem Tora ${ }^{1}$, Asdesach Tafese ${ }^{1}$, Tadele Genu ${ }^{1}$, Tamirat Kaba ${ }^{3}$, \\ Tariku Jibat Beyene ${ }^{1,4}$, Takele Beyene ${ }^{1}$, Mesula Geloye Korsa ${ }^{1,5}$, Fanos Tadesse', Lieven De Zutter ${ }^{6}$, \\ Bruno Maria Goddeeris ${ }^{6,7}$ and Eric Cox ${ }^{6}$
}

\begin{abstract}
Background: Ethiopia bears the largest burden of foodborne diseases in Africa, and diarrheal diseases are the second leading causes of premature deaths. Enterohemorrhagic Escherichia coli $\mathrm{O} 157$ causes an asymptomatic infection to severe diarrhea and/or hemolytic-uremic syndrome in humans.

Methods: A total of 440 beef carcass and in-contact surface swabs from 55 butcher shops and 85 minced beef samples from 40 restaurants in central Ethiopia were collected and examined for the presence of E. coli O157. Standard microbiological methods were used to isolate and identify E. coli O157 and to characterize the antimicrobial resistance of the isolates.
\end{abstract}

Results: E. coli 0157 was detected in $4.5 \%$ carcass swabs $(n=5)$ and $3.6 \%$ cutting board swabs $(n=4)$ samples from butcher shops. E. coli $\mathrm{O} 157$ was not detected in any of the minced beef samples obtained from restaurants. All isolates $(n=9)$ were $100 \%$ susceptible to five drugs, but five isolates were resistant to amoxicillin, two isolates to streptomycin and three isolates to chloramphenicol. One isolate was resistant to two drugs and another to three drugs.

Conclusions: The present study shows a low prevalence of E. coli O157 in beef sold at butcher shops. Nevertheless, given the low infective dose of this pathogen and the deep-rooted tradition of consuming raw or undercooked beef, the current prevalence should not be considered lightly from a public health perspective.

Keywords: Antimicrobial susceptibility, Beef, Butcher shops, Escherichia coli O157, Minced beef, Restaurants

\section{Background}

In the $21^{\text {st }}$ century, foodborne diseases have become one of the important issues all over the world [1]. Due to poor infrastructure and low level of awareness, this problem is worse in developing countries [2]. Major pathogenic microorganisms that frequently have been associated with foods of animal origin include Enterohemorrhagic Escherichia coli O157. In humans this pathogen causes asymptomatic infection to severe diarrhea and/or hemolytic-uremic syndrome (HUS) [3]. Human infections with $E$. coli $\mathrm{O} 157$ have been mostly associated with the

\footnotetext{
* Correspondence: ashenafi.feyisa1@gmail.com

${ }^{1}$ College of Veterinary Medicine and Agriculture, Addis Ababa University, Bishoftu, Ethiopia

${ }^{2}$ Department of Animal Sciences, University of Florida, Gainesville, FL, USA Full list of author information is available at the end of the article
}

consumption of contaminated and improperly cooked minced beef and unpasteurized cow milk [4]. Butcher houses and restaurants are frequently incriminated as sources of E. coli O157 for human infections [5].

Ethiopia ranks second after Nigeria in the health burden of zoonotic diseases in Africa [6]. This country is located in a sub-region that experiences the second highest foodborne disease burden in the world, where E. coli $\mathrm{O} 157$ is one of the leading causes of foodborne disease disability adjusted life years [7]. In Ethiopia, years of life lost due to diarrheal diseases was 2.6 million in 2010, and diarrheal diseases are the second leading cause of premature death after lower respiratory infections [8]. Information about human infections with $E$. coli $\mathrm{O} 157$ is limited in this country, however, in a study conducted on 422 diarrheic children under 5 years in northern part of Ethiopia, E. coli 
O157:H7 was isolated from 59 (28.9\%) of the children [9]. The habit of consuming raw and/or undercooked meat is one of the factors that exacerbate the transmission of foodborne pathogens including E. coli $\mathrm{O} 157$ in the country. Sufficient heating of meat kills these organisms [4]; however, in Ethiopia, most people prefer to eat raw or undercooked beef (locally called kitfo, dulet, and kurt).

Treatment of Enterohemorrhagic E. coli infections with antibiotics may worsen the illness, presumably by breaking up the bacteria with the release of more toxins and increased toxin production [10]. However, early administration using some antimicrobials is effective [11]. Unfortunately, inappropriate ways of antimicrobial uses have contributed to the increase in antimicrobial resistance [12].

In Ethiopia, only few small-scale studies estimating the prevalence and/or assessing the antimicrobial sensitivity profile of enterohemorrhagic E. coli $\mathrm{O} 157$ in feces, skin swabs and carcasses of sheep, goats, and cattle at abattoirs were conducted [13-16]. But studies at the level of consumption particularly in butcher shops and restaurants is lacking. Consequently, this study was designed to address the information gap pertaining to the prevalence and antibiotic susceptibility profiles of $E$. coli $\mathrm{O} 157$ in beef carcass and minced beef at butcher shops and restaurants respectively in central Ethiopia.

\section{Methods}

\section{Study design and sample collection}

From December 2013 to April 2014, carcass and carcass in-contact surface swabs of 55 randomly selected butcher shops, and minced beef samples of 40 randomly selected restaurants were collected in four cities (Addis Ababa, Bishoftu, Batu, and Holetta) in central Ethiopia.

These cities have municipal abattoirs which render slaughter services to their respective dwellers. Butcher shops and restaurants get their beef from cattle slaughtered in the abattoirs of their respective cities. Nevertheless, back yard or illegal slaughtering of animals is a common practice. The abattoirs are barely equipped with necessary facilities, and shortage of clean water is one of the chronic problems for most abattoirs in the country. In addition, the sanitary condition of most restaurants and butcher shops is poor; generally, such food catering firms are loosely monitored and regulated. In Ethiopia, fresh beef cuts are commonly purchased from butcher shops and are consumed at home or at the same butcher shop, either cooked or raw. In butcher's shops, a beef carcass is kept in open-air at environmental temperature (in Addis Ababa 7 to $25{ }^{\circ} \mathrm{C}$ daily temperature).

The butcher shops and restaurants in each city were selected by a simple random sampling technique, using lists obtained from city administrations of the respective cities as sampling frames. When visiting each selected butcher shop and restaurant, the purpose of the study was explained to the manager, and a letter from the College of Veterinary Medicine and Agriculture Addis Ababa University demonstrated the approval and credibility of our work. From each butcher shop on average eight samples were collected on two separate days. A total of 440 swab samples consisting of 110 samples from beef carcass, knife, cutting board, and butcher's hands at butcher shops, respectively, and 85 minced beef (locally also called kitfo) samples from restaurants were collected (Table 1). Beef carcasses were swabbed following the method described in ISO17604 (2003). A sterile cotton tipped swab $(2 \mathrm{X} 3 \mathrm{~cm})$ fitted with shaft, was first soaked in an approximately $10 \mathrm{ml}$ of buffered peptone water (BPW; Oxoid, Hampshire, UK) and subsequently rubbed horizontally and vertically several times on the carcass surface. After the rubbing process, the shaft was broken by pressing it against the inner wall of the test tube leaving the cotton swab inside the test tube. The whole surface of the carcass was swabbed by one swab, and swabs from multiple carcasses from the same butcher shop were pooled together. Carcass in-contact surfaces including knife, butcher's hands and cutting board swabs were obtained by swabbing them using a cotton swab pre-moistened in BPW. The junction of the handle and blade of all knives in each butcher shop was swabbed and pooled together. Similarly, both sides of the two hands of the butcher, and the whole surface of the wooden cutting board were swabbed. The carcass swab, the butcher's hands swab, the cutting board swab and the knife swab were kept separately. The minced beef samples were taken from ready-to-eat undercooked $(n=45)$ and raw minced beef $(n=40)$ at the selected restaurants. All samples were transported in cold boxes to the laboratory. The samples were stored at 4 to $7{ }^{\circ} \mathrm{C}$ and analyzed within 6 to $12 \mathrm{~h}$ as described in ISO 16654:2001.

\section{Sample processing}

Ninety $\mathrm{ml}$ of modified tryptone soy broth supplemented with novobiocin (mTSB $+\mathrm{N}$; Oxoid) were added to $10 \mathrm{ml}$ swab sample. Conversely, $25 \mathrm{~g}$ of each minced beef sample were collected in a Stomacher bag. After adding $225 \mathrm{ml} \mathrm{mTSB}+\mathrm{N}$, each sample was homogenized using a Stomacher 400 (Seward Medical, England) for two minutes and transferred into a sterile flask. After incubation at $41.5 \pm 0.5{ }^{\circ} \mathrm{C}$ for $24 \mathrm{~h}$, all enrichment broths were plated onto sorbitol MacConkey agar (Oxoid) supplemented with $0.05 \mathrm{mg} / \mathrm{l}$ cefixime and $2.5 \mathrm{mg} / \mathrm{l}$ potassium tellurite (Oxoid) (SMAC-CT) and incubated at $37{ }^{\circ} \mathrm{C}$ for 18 to $24 \mathrm{~h}$. Multiple non-sorbitol fermenting typical $E$. coli colonies from a plate were streaked out on the SMAC-CT agar and incubated for 
Table 1 Escherichia coli 0157 isolated from carcass, hand, knife, and cutting board swabs and minced beef in central Ethiopia

\begin{tabular}{|c|c|c|c|c|c|}
\hline \multirow[b]{2}{*}{ Sample types } & \multicolumn{5}{|c|}{ Number of positive samples/number of tested samples } \\
\hline & Addis Ababa & Bishoftu & Batu & Holetta & Total \\
\hline Carcass swab & $1 / 25$ & $2 / 30$ & $1 / 25$ & $1 / 30$ & $5 / 110$ \\
\hline Hand swab & $0 / 25$ & $0 / 30$ & $0 / 25$ & $0 / 30$ & $0 / 110$ \\
\hline Knife swab & $0 / 25$ & $0 / 30$ & $0 / 25$ & $0 / 30$ & $0 / 110$ \\
\hline Cutting board swab & $1 / 25$ & $1 / 30$ & $0 / 25$ & $2 / 30$ & $4 / 110$ \\
\hline Minced beef & $0 / 20$ & $0 / 25$ & $0 / 20$ & $0 / 20$ & 0/85 \\
\hline Total & $2 / 120$ & $3 / 145$ & $1 / 120$ & $3 / 140$ & $9 / 525$ \\
\hline
\end{tabular}

$24 \mathrm{~h}$ at $37^{\circ} \mathrm{C}$ for the confirmatory test. All colonies that did not ferment sorbitol on the SMAC-CT agar underwent a slide agglutination test using an E. coli O157 latex test kit (Oxoid) and were considered E. coli O157 positive when precipitation occurred within one minute.

\section{Antimicrobial susceptibility testing}

The E. coli O157 isolates were tested for antimicrobial susceptibility to a panel of the following ten antimicrobial agents: amoxicillin (AMX $25 \mu \mathrm{g}$ ), kanamycin (KAN $30 \mu \mathrm{g}$ ), trimethoprim-sulfamethoxazole (SXT $25 \mu \mathrm{g}$ ), chloramphenicol (CHL $30 \mu \mathrm{g})$, ciprofloxacin (CPR $5 \mu \mathrm{g}$ ), streptomycin (STR $10 \mu \mathrm{g}$ ), nalidixic acid (NA $30 \mu \mathrm{g}$ ), cefoxitin (CFX $30 \mu \mathrm{g}$ ), tetracycline (TTC $30 \mu \mathrm{g}$ ), and nitrofurantoin (NTR $50 \mu \mathrm{g}$ ) using the disc diffusion method according to the guidelines for Clinical and Laboratory Standards Institute [17]. All test discs were obtained from Oxoid. The isolates were classified as sensitive, intermediate, or resistant using the breakpoints of the CLSI. The standard reference strain of $E$. coli ATCC 25922, sensitive to all tested antimicrobial agents, was used as the control strain.

\section{Statistical analysis}

The data were analyzed using STATA Version 11.0 (STATA corp. College Station, TX, USA). Descriptive statistics (estimation of proportions) were used to summarize the prevalence of E. coli $\mathrm{O} 157$ and antimicrobial sensitivity patterns of the isolates.

\section{Results}

E. coli 0157 isolated from butcher shops and restaurants Out of the 525 collected samples, 60 of them had E. coli O157 suspect colonies on the CT- SMAC plates (40 samples from the butcher shops and 20 samples from the restaurants). Only nine (1.7\%, 95\% CI: $0.8-3.3 \%)$ of the 525 examined samples were confirmed to be positive for E. coli O157 (Table 1). Two samples (one carcass swab and one cutting board swab) obtained from the same butcher shop during the same visit were positive for E. coli O157, but in the other cases, the positive carcass swabs and the positive cutting boards swabs were from different butcher shops. $E$. coli $\mathrm{O} 157$ was not detected in any of the minced beef samples.

Antimicrobial susceptibility profiles of $E$. coli 0157 isolates All isolates were susceptible (100\%) to five of the ten antimicrobial agents (trimethoprim-sulfamethoxazole, tetracycline, cefoxitin, kanamycin, and nalidixic acid; Table 2). Conversely, 5, 3, and 2 of the isolates were resistant to amoxicillin, streptomycin, and chloramphenicol, respectively. Only two of the isolates were susceptible to all examined antimicrobial agents. One isolate from the carcass was resistant to amoxicillin and chloramphenicol, and one isolate from the cutting board was resistant to amoxicillin, chloramphenicol, and streptomycin.

\section{Discussion}

Food borne infections are major health concerns in developing countries including Ethiopia. Information on incidence of these infections and their susceptibility to antimicrobials helps policy makers to develop appropriate strategies in terms of prevention, treatment and control. In this study, 4.5\% (5/110) carcass swabs were positive for E. coli O157. Tendencies for higher prevalences were observed in previous studies. In one of the studies, eight of 86 beef samples (i.e. 9.3\%) collected from butcher shops in central Ethiopia were positive [14]. Hiko et al. [14] examined meat samples while we tested swabs of carcass surfaces and carcass in-contact surfaces. Likewise, Mersha, Asrat [18] found at an export abattoir in central Ethiopia that 8.1\% (14/172) of sheep and goat carcass surface swabs taken before washing and $8.7 \%(15 / 172)$ of carcass surface swabs after washing were contaminated by E. coli O157:H7. Also, the prevalence of E. coli $\mathrm{O} 157$ in the carcass surface swabs of our study (4.5\%) was similar to reports from eastern Ethiopia $(2.65 \%, 3 / 113$ beef carcass surface swabs) at Haramaya University slaughter house [16] and from Turkey (2\%, $2 / 100$ beef carcass surface swabs) at two commercial abattoirs in Samsun Province [19], and from the UK (2.9\%, 29/1877 samples of lamb products) at butcher shops in South Yorkshire. However, the prevalence in 
Table 2 Antimicrobial susceptibility profiles of nine Escherichia coli 0157 isolates of carcass and cutting board samples collected from butcher shops in four cities in central Ethiopia

\begin{tabular}{|c|c|c|c|c|c|c|c|c|c|}
\hline \multirow[t]{2}{*}{ Antimicrobial agents } & \multicolumn{3}{|c|}{ Holetta } & \multicolumn{3}{|c|}{ Bishoftu } & \multirow{2}{*}{$\begin{array}{l}\text { Addis Ababa } \\
\text { Ca }\end{array}$} & \multicolumn{2}{|c|}{ Batu } \\
\hline & $\overline{C a^{a}}$ & $\mathrm{Ca}$ & $\overline{C B^{a}}$ & $\overline{\mathrm{Ca}}$ & $\mathrm{Ca}$ & $C B$ & & $\overline{C B}$ & $\mathrm{Ca}$ \\
\hline Amoxicillin & $1^{\mathrm{b}}$ & I & I & $\mathrm{R}^{\mathrm{b}}$ & I & $R$ & $\mathrm{R}$ & $R$ & $\bar{R}$ \\
\hline Cefoxitin & $S^{b}$ & S & S & S & S & S & S & $S$ & S \\
\hline Chloramphenicol & S & S & S & $\mathrm{R}$ & I & $\mathrm{R}$ & S & S & S \\
\hline Ciprofloxacin & S & S & S & S & S & I & S & S & I \\
\hline Kanamycin & S & S & S & S & S & S & S & S & S \\
\hline Nalidixic acid & S & S & S & S & S & S & S & $S$ & S \\
\hline Nitrofurantoin & S & S & S & S & S & S & I & $S$ & I \\
\hline Streptomycin & S & S & $R$ & I & $\mathrm{R}$ & $R$ & S & । & I \\
\hline Tetracycline & S & S & S & S & S & S & S & S & S \\
\hline Trimethoprim-Sulfamethoxazole & S & S & S & S & $S$ & S & S & S & S \\
\hline
\end{tabular}

${ }^{a}$ Sample types: $C a$ carcass, $C B$ cutting board; ${ }^{b}$ Antimicrobial susceptibility patterns, $R$ resistant, $l$ intermediate resistant, $S$ susceptible

beef products at the same butcher shops tended to be lower (1.1\%, 36/3216 samples of beef products) [3]. Nevertheless differences in prevalences could have been due to the limited sample size in our and several of the other studies.

In this study, E. coli $\mathrm{O} 157$ was isolated from $3.6 \%$ $(4 / 110)$ of the surface swabs of wooden cutting boards; however, none of the swabs from butcher hands and knives were positive. In a similar kind of study conducted in Pakistan, E. coli O157:H7 was not detected in surface swabs (knives, wooden boards, weighing scales, and meat mincers) taken from 30 individual retail meat outlet markets [20]. In our study, in one case both the beef carcass surface swab and the cutting board swab collected during the same visit to the same butcher shop were positive, indicating the possible contamination of the wooden board by the carcass or vice versa; however, in other three cases, E. coli O157 was not detected in the carcass samples from butcher shops where the cutting boards were positive. The isolation of E. coli O157 from the carcass in-contact material although the carcass itself was negative, may suggest the presence of other potential sources of contamination in butcher shops like cleaning water or inadequate cleaning and disinfection of the cutting boards leading to possible biofilm formation by the organisms on the wooden board. Indeed, $E$. coli $\mathrm{O} 157$ has been isolated from water samples in Ethiopia [13, 18] and biofilm formation of E. coli $\mathrm{O} 157$ in various food contact surfaces and tolerance to sanitizing reagents has been reported [21, 22]. E. coli O157 contaminated cutting boards can be an important source of cross contamination and may pose a significant public health risk.

E. coli $\mathrm{O} 157$ was not detected in the 85 minced beef samples from the 40 restaurants, which is in agreement with reports from Turkey [23] and Seattle, USA [24]. By contrast, $11.25 \%$ of cooked beef doner kebabs in Turkey [25] and 3.8\% of minced beef in Argentina [26] were contaminated by $E$. coli O157:H7. In our study, the inability of isolating E. coli $\mathrm{O} 157$ from the ground beef samples where the contamination of beef carcass at butcher shops and abattoirs is not uncommon could be attributed to the way kitfo is prepared. Minced beef is seasoned with butter and other spices to prepare kitfo. Antimicrobial effects of some Ethiopian spices against $E$. coli and other organisms have been demonstrated [27]. The spice blends may stress the organisms, which may make the isolation of $E$. coli $\mathrm{O} 157$ from contaminated samples difficult. However, the stressed organisms retain their pathogenicity and thus pose risk to humans, given the fact that E. coli $\mathrm{O} 157$ has a low infective dose [11]. The small number of samples considered in the current study calls for a further large scale study to estimate the real prevalence of E. coli O157 in kitfo, and to investigate whether the kitfo preparation process has a possible antibacterial effect. Before such a study can be done an evaluation of the efficiency of the applied detection method to isolate possible sub-lethal injured E. coli O157, caused by spices in such beef product, is recommended.

In the present study some of the isolates were resistant to amoxicillin $(n=5)$, streptomycin $(n=3)$, and chloramphenicol $(n=2)$. While previous studies from Ethiopia and other countries reported resistance to amoxicillin and/or streptomycin, the resistance observed against chloramphenicol in the current study is in contrast to the previous reports of $100 \%$ susceptibility to this antibiotic $[13,14,16,28]$. On the other hand, resistance to chloramphenicol and other drugs have been reported elsewhere $[29,30]$. In the present study, one isolate was resistant to two antimicrobials (amoxicillin and chloramphenicol) and another isolate to three antimicrobials 
(amoxicillin, chloramphenicol, and streptomycin), which is in agreement with previous studies $[13,14,16,29,31]$. In current study, a low level of antimicrobial resistance was observed in comparison to previous studies; this might be related to the fewer number of antimicrobial panels we used. However, the current finding has a significant public health implication.

Among the antimicrobials we examined, trimethoprimsulfamethoxazole is one of the $\beta$-lactams antibiotics that their prescription for E. coli O157:H7 infections is debatable, as these drugs may surge the risk of HUS in children [32-34]. On the other hand, another study shows that in the early stage of infections these antibiotics do not entail risk [35]. Some of the drugs we tested such as amoxicillin, cifoxitin, and trimethoprim-sulfamethoxasole can increase the risk of HUS; and thus they are not recommended for the treatment of infections caused by E.coli O157:H7. Fluoroquinolones family drugs such as ciprofloxacin and nalidixic acid are commonly prescribed for adults but not for children. However, two of our isolates showed intermediate resistant to ciprofloxacin which is alarming.

\section{Conclusions}

In conclusion, the present study demonstrates low prevalence of E. coli $\mathrm{O} 157$ (1.7\%) in butcher shops in central Ethiopia. Nevertheless, given the low infective dose of E. coli $\mathrm{O} 157$ and the deep-rooted tradition of consuming raw or undercooked beef in the society, the current prevalence should be considered important from a public health perspective and surveillance to monitor E. coli $\mathrm{O} 157$ and other pathogens in butcher shops should be organized. E. coli $\mathrm{O} 157$ was detected on cutting boards in four butcher shops, indicating that such equipment can function as a source for contamination of beef. In order to prevent such contamination butchers have to improve their hygiene practice. E. coli $\mathrm{O} 157$ was not detected in the kitfo samples from restaurants. Presence of spices in kitfo may lead to sub-lethal E. coli O157 cells leading to false-negative results. The isolates were susceptible to most of the drugs used in the in vitro test; however, the resistance observed against chloramphenicol in the current study is in contrast to the previous three studies in Ethiopia.

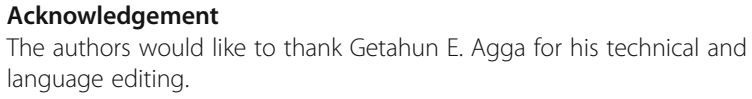

\section{Funding}

This research was funded by Addis Ababa University, Ethiopia and the VLIR-UOS funded project "Promotion of the PhD program in Veterinary Public Health at the faculty of Veterinary Medicine, AAU" between Ethiopia and Flanders (Belgium).

\section{Authors' contributions}

AFB participated in study design, sample collection, data analysis, and write up of the draft and final version of the manuscript. ATF involved in study design, sample collection, and laboratory analysis. ET collected and analyzed samples, and wrote the first draft of the manuscript. AT, TG, and TK participated in sample collection and laboratory analysis. TB involved in study design and laboratory analysis. TJB, MG, FT, LDZ, BMG, and EC involved in the study design. All authors contributed to the final version of the manuscript and approved the submission. BMG was the promotor of the VLIR-UOS funded Ethiopian-Belgian project.

\section{Competing interests}

The authors declare that they have no competing interests.

Consent for publication

Not applicable.

\section{Ethics approval and consent to participate}

This research was approved by the Academic Commission of College of Veterinary Medicine and Agriculture Addis Ababa University. The study purpose was explained to participants and verbal agreement was obtained before proceeding to the study.

\section{Author details}

${ }^{1}$ College of Veterinary Medicine and Agriculture, Addis Ababa University, Bishoftu, Ethiopia. ${ }^{2}$ Department of Animal Sciences, University of Florida, Gainesville, FL, USA. ${ }^{3}$ Holetta Research Center, Ethiopian Institute of Agricultural Research, Holetta, Ethiopia. ${ }^{4}$ Business Economics Group, Wageningen University, Hollandseweg 1, 6706 KN Wageningen, The Netherlands. ${ }^{5}$ The Asia-Pacific Centre for Animal Health, Faculty of Veterinary and Agricultural Sciences, The University of Melbourne, Parkville, VIC, Australia. ${ }^{6}$ Faculty of Veterinary Medicine, University of Gent, Ghent, Belgium. ${ }^{7}$ Division Animal and Human Health Engineering, Katholieke Universiteit Leuven, Leuven, Belgium.

Received: 14 August 2016 Accepted: 24 February 2017

Published online: 03 March 2017

\section{References}

1. Scott E. Food safety and foodborne disease in $21^{\text {st }}$ century homes. Can J Infect Dis. 2003;14(5):277-80.

2. Zhao C, Ge B, De Villena J, Sudler R, Yeh E, Zhao S, et al. Prevalence of Campylobacter spp., Escherichia coli, and Salmonella serovars in retail chicken, turkey, pork, and beef from the Greater Washington, D.C., area. Appl Environ Microbiol. 2001;67(12):5431-6.

3. Chapman PA, Siddons CA, Cerdan Malo AT, Harkin MA. A 1 year study of Escherichia coli 0157 in raw beef and lamb products. Epidemiol Infect. 2000;124(2):207-13.

4. Doyle MP. Escherichia coli O157:H7 and its significance in foods. Int J Food Microbiol. 1991;12(4):289-301.

5. Pennington H. Escherichia coli O157. Lancet. 2010;376(9750):1428-35.

6. Grace D, Mutua F, Ochungo P, Kruska R, Jones K, Brierley L, et al. Mapping of poverty and likely zoonoses hotspots. 2012. https://cgspace.cgiar.org/ handle/10568/21161. Cited 24 Jan 2016.

7. Havelaar AH, Kirk MD, Torgerson PR, Gibb HJ, Hald T, Lake RJ, et al. World Health Organization Global Estimates and Regional Comparisons of the Burden of Foodborne Disease in 2010. Plos Med. 2015;12(12):e1001923.

8. GBD. Global burden of diseases, injuries, and risk factors study 2010. Ethiopia: GDB profile; 2016. healthmetricsandevaluation.org. cited January 242016.

9. Adugna A, Kibret M, Nibre E, Adal M. Antibiogram of E. coli serotypes isolated from children aged under five with acute diarrhea in Bahir Dar town. Afr Health Sci. 2015;15(2):656-64.

10. McEvoy JM, Doherty AM, Sheridan JJ, Thomson-Carter FM, Garvey P, McGuire L, et al. The prevalence and spread of Escherichia coli 0157:H7 at a commercial beef abattoir. J Appl Microbiol. 2003;95(2):256-66.

11. De Boer E, Heuvelink AE. Methods for the detection and isolation of Shiga toxin-producing Escherichia coli. Symp Ser Soc Appl Microbiol. 2000:29:133S-43S

12. Wong CS, Jelacic S, Habeeb RL, Watkins SL, Tarr PI. The risk of the hemolytic-uremic syndrome after antibiotic treatment of Escherichia coli 0157:H7 infections. N Engl J Med. 2000;342(26):1930-6. 
13. Dulo F, Feleke A, Szonyi B, Fries R, Baumann MP, Grace D. Isolation of multidrugresistant Escherichia coli $\mathrm{O} 157$ from goats in the Somali region of Ethiopia: a cross-sectional, Abattoir-based study. Plos One. 2015;10(11):e0142905.

14. Hiko A, Asrat D, Zewde G. Occurrence of Escherichia coli O157:H7 in retail raw meat products in Ethiopia. J Infect Dev Ctries. 2008;2(5):389-93.

15. Marshall KM, Niebuhr SE, Acuff GR, Lucia LM, Dickson JS. Identification of Escherichia coli O157:H7 meat processing indicators for fresh meat through comparison of the effects of selected antimicrobial interventions. J Food Prot. 2005;68(12):2580-6.

16. Taye M, Berhanu T, Berhanu Y, Tamiru F, Terefe D. Study on carcass contaminating $E$ coli in apparently healthy slaughtered cattle in Haramaya University slaughter house with special emphasis on E. coli 0157:H7. J Vet Sci Technol. 2013;4:132

17. CLSI. Clinical and Laboratory standard Institute. Performance Standards for Antimicrobial Susceptibility Testing: Seventeenth informational supplement: CLSI Document M100-S17 (ISBN 1-56238-625-5). January 2007.

18. Mersha G, Asrat D, Zewde BM, Kyule M. Occurrence of Escherichia coli O157: $\mathrm{H} 7$ in faeces, skin and carcasses from sheep and goats in Ethiopia. Lett Appl Microbiol. 2010;50(1):71-6.

19. Inat $\mathrm{G}$, Siriken B. Detection of Escherichia coli $\mathrm{O} 157$ and Escherichia coli 0157:H7 by the immunomagnetic separation technique and st $x 1$ and stx2 genes by multiplex PCR in slaughtered cattle in Samsun Province, Turkey. J Vet Sci. 2010;11(4):321-6.

20. Hassan Ali N, Farooqui A, Khan A, Khan AY, Kazmi SU. Microbial contamination of raw meat and its environment in retail shops in Karachi, Pakistan. J Infect Dev Ctries. 2010;4(6):382-8.

21. Silagyi K, Kim SH, Lo YM, Wei Cl. Production of biofilm and quorum sensing by Escherichia coli O157:H7 and its transfer from contact surfaces to meat, poultry, ready-to-eat deli, and produce products. Food Microbiol. 2009;26(5):514-9.

22. Wang R, Bono JL, Kalchayanand N, Shackelford S, Harhay DM. Biofilm formation by Shiga toxin-producing Escherichia coli O157:H7 and Non-0157 strains and their tolerance to sanitizers commonly used in the food processing environment. J Food Prot. 2012;75(8):1418-28.

23. Cadirci O, Siriken B, Inat G, Kevenk TO. The prevalence of Escherichia coli O157 and 0157:H7 in ground beef and raw meatball by immunomagnetic separation and the detection of virulence genes using multiplex PCR. Meat Sci. 2010;84(3):553-6.

24. Tarr PI, Tran NT, Wilson RA. Escherichia coli O157:H7 in retail ground beef in Seattle: results of a 1-year prospective study. J Food Prot. 1999;62(2):133-9.

25. Ulukan Z, Çavli P, Tuzcu M. Detection of E. coli O157:H7 from Beef Doner Kebabs Sold in Kars. GU J Sci. 2006;19:99-104.

26. Chinen I, Tanaro JD, Miliwebsky E, Lound LH, Chillemi G, Ledri S, et al. Isolation and characterization of Escherichia coli 0157:H7 from retail meats in Argentina. J Food Prot. 2001;64(9):1346-51.

27. Hussien J, Teshale C, Mohammed J. Assessment of antimicrobial effects of some Ethiopian aromatic spices and herb hydrosols. Int J Pharmacol. 2011;7(5):635-40

28. Srinivasan V, Nguyen L, Headrick S, Murinda S, Oliver S. Antimicrobial resistance patterns of Shiga toxin-producing E. coli O157:H7 and O157:H7 from different origins. Microb Drug Resist. 2007;13(1):44-51.

29. Meng J, Zhao S, Doyle MP, Joseph SW. Antibiotic resistance of Escherichia coli 0157:H7 and 0157:NM isolated from animals, food, and humans. J Food Prot. 1998:61(11):1511-4.

30. Al-Wabel NA. Antibiotic susceptibility of $E$. coli O157:H7 isolated from beef burger. Bull Pharm Sci. 2007;30(2):131-4.

31. Osaili TM, Alaboudi AR, Rahahlah M. Prevalence and antimicrobial susceptibility of Escherichia coli O157:H7 on beef cattle slaughtered in Amman abattoir. Meat Sci. 2013;93(3):463-8.

32. Safdar $\mathrm{N}$, et al. Risk of hemolytic uremic syndrome after antibiotic treatment of Escherichia coli O157: H7 enteritis: a meta-analysis. JAMA. 2002;288(8):996-1001.

33. Wong CS, et al. The risk of the hemolytic-uremic syndrome after antibiotic treatment of Escherichia coli O157: $\mathrm{H7}$ infections. N Engl J Med. 2000;342(26):1930-6

34. Wong CS, Mooney JC, Brandt JR, Staples AO, Jelacic S, Boster DR, Watkins SL, Tarr PI. Risk factors for the hemolytic uremic syndrome in children infected with Escherichia coli O157: H7: a multivariable analysis. Clin Infect Dis. 2012;55(1):33-41

35. Panos $G$, Betsi G, Falagas M. Systematic review: are antibiotics detrimental or beneficial for the treatment of patients with Escherichia coli O157: H7 infection? Aliment Pharmacol Ther. 2006;24(5):731-42.

\section{Submit your next manuscript to BioMed Central and we will help you at every step:}

- We accept pre-submission inquiries

- Our selector tool helps you to find the most relevant journal

- We provide round the clock customer support

- Convenient online submission

- Thorough peer review

- Inclusion in PubMed and all major indexing services

- Maximum visibility for your research

Submit your manuscript at www.biomedcentral.com/submit
Biomed Central 